\title{
An overview of molecular acceptors for organic solar cells
}

\author{
Piétrick Hudhomme ${ }^{\mathrm{a}}$ \\ L'UNAM Université, Université d'Angers, Laboratoire MOLTECH-Anjou, CNRS UMR 6200, 2 boulevard Lavoisier, \\ 49045 Angers, France
}

Received: 18 January 2013 / Accepted: 16 April 2013

Published online: 8 July 2013

(C) Hudhomme, published by EDP Sciences, 2013

\begin{abstract}
Organic solar cells (OSCs) have gained serious attention during the last decade and are now considered as one of the future photovoltaic technologies for low-cost power production. The first dream of attaining $10 \%$ of power coefficient efficiency has now become a reality thanks to the development of new materials and an impressive work achieved to understand, control and optimize structure and morphology of the device. But most of the effort devoted to the development of new materials concerned the optimization of the donor material, with less attention for acceptors which to date remain dominated by fullerenes and their derivatives. This short review presents the progress in the use of non-fullerene small molecules and fullerene-based acceptors with the aim of evaluating the challenge for the next generation of acceptors in organic photovoltaics.
\end{abstract}

\section{Introduction}

The conversion of solar energy into electrical energy is probably one of the most exciting research challenges nowadays. The recent advances in the development of OSCs using carbon-based materials constitute an attractive alternative to silicon-based photovoltaics, essentially because of their potentially low cost and their ease of manufacture. In the last two decades, this tendency to move progressively from inorganic to organic-based materials for photovoltaic applications has emerged as the third generation of photovoltaic materials. These devices that contain organic materials in the active layer include dye-sensitized solar cells [1-4] and donor-acceptor heterojunction based solar cells [5-9]. This last topic has recently been the subject of intensive academic interest and has particularly captured a huge amount of industrial attention due to the rapid increase in power conversion efficiencies (PCE) of these solar cells and their potential for developing flexible, light-weight devices using low-cost production methods. A first significant advance was the contribution made in 1986 with the application of the $\mathrm{p}-\mathrm{n}$ junction approach in organic photovoltaic cells [10]. A double-layer solar cell with the efficiency close to $1 \%$ was obtained by thermal evaporation of successive layers of copper phthalocyanine and a perylene-based small molecule playing the role of donor and acceptor, respectively. A major breakthrough arose with the discovery of fullerene $\mathrm{C}_{60}$ in 1985, followed by the demonstration of the photophysical, photochemical and photoinduced elec-

a e-mail: pietrick.hudhomme@univ-angers.fr tron transfer properties of fullerene derivatives. In particular, it was demonstrated in 1992 that a $\pi$-conjugated polymer was able to transfer electrons efficiently to a $\mathrm{C}_{60}$ core giving rise to long-lived charge-separated states [11]. Considerable improvements in fundamental understanding, device construction, processing of the active layer, and optimization of new materials [12] have been made during these last few years and a certified $10.6 \%$ PCE was recently reported [13]. Extensive studies have been aimed at designing optimal conjugated polymers as electron donors, and this development has played a crucial role in the dramatic improvement of OSC performance in recent years. On the other hand, fullerene derivatives were rapidly considered as the most efficient acceptors and much less attention has been devoted to other classes of n-type acceptors. In this paper we present a short and nonexhaustive overview of non-fullerene small-molecules in a first part and fullerene-based acceptors in a second part which are developed so far. These two different families of n-type materials used in OSCs, with small-molecules non-fullerene materials $[14,15]$ and fullerene based acceptors $[16,17]$, have been recently and separately reviewed.

\section{Principles of organic solar cells}

Organic solar cells, based on heterojunctions using p-type donor (D) and n-type acceptor (A) semiconductors, are fabricated by sandwiching the p-type and n-type materials between two different electrodes, such as for examples Indium Tin Oxide (ITO) and aluminium layers for the anode and cathode, respectively. Donor and acceptor 
Planar - heterojunction

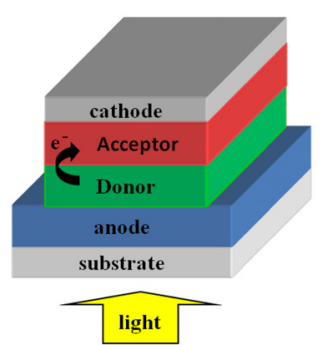

Bulk - heterojunction

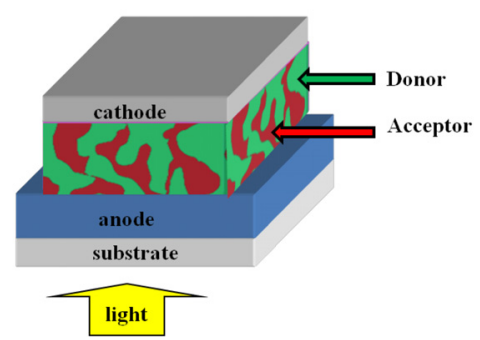

Fig. 1. Schematic representation of an OSC with a planar heterojunction (bilayer structure) or bulk-heterojunction (interpenetrating network of blended donor and acceptor materials).

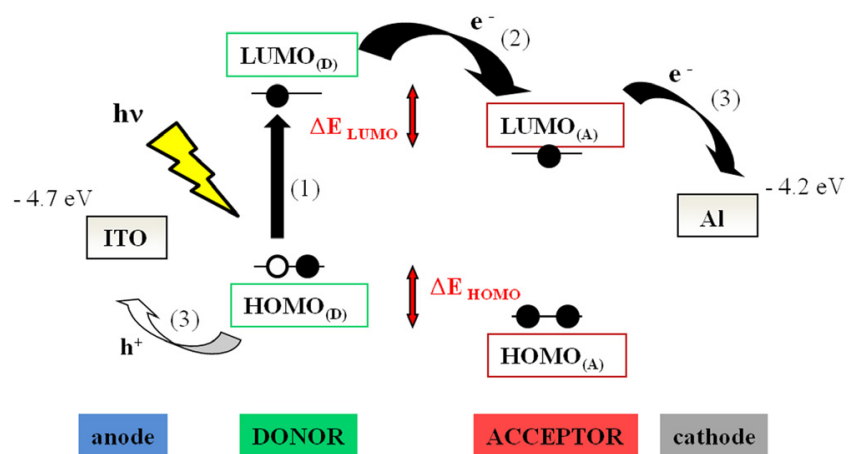

Fig. 2. HOMO-LUMO energy level diagram of donor and acceptor materials in an OSC.

materials can be deposited as two distinct layers (planar p-n heterojunction) or blended in an homogeneous mixture throughout an interpenetrating network known as bulk-heterojunction (BHJ) which presents a larger interfacial area (Fig. 1). With the aim of covering more effectively the solar spectrum, another useful approach consists in stacking multiple photoactive layers with complementary absorption spectra in series to reach a tandem device [18]. From the technological point of view, the potential for low cost of these OSCs stems from the ability to produce these devices using high-throughput vacuum processing for small molecular weight based solar cells or roll-to-roll solution processing methods for polymer solar cells [19].

When incident photons are absorbed by the active layer, the photovoltaic effect is built following a precise sequence of events: (1) excitation of the donor upon absorption of light; (2) electron transfer from the donor to the acceptor component and formation of an electron-hole pair (exciton) with the positive charge (hole) on the donor and negative charge on the acceptor; and (3) diffusion then migration of the exciton at the donor/acceptor interface and collection of the charges at the corresponding electrodes [20].

From a theoretical point of view, the principal feature of the $p-n$ heterojunction is the built-in potential at the interface between both materials presenting a difference of electronegativities. Photoexcitation of the absorbing material causes, through a photoinduced electron transfer process, the promotion of an electron from the highest occupied molecular orbital (HOMO) of the donor to the
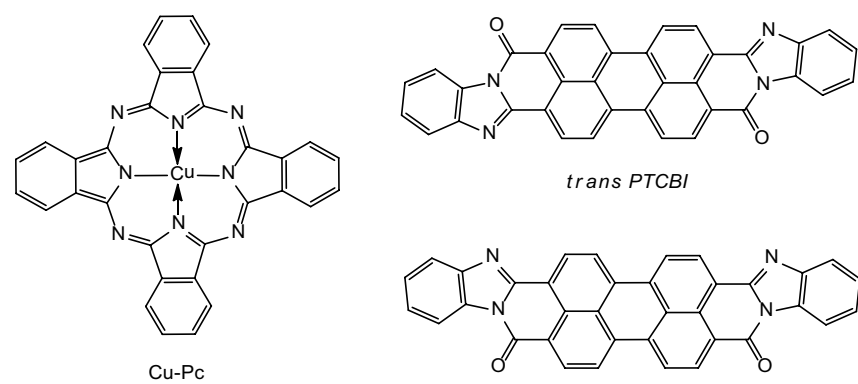

trans PTCBI

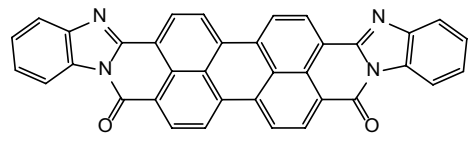

cis PTCBI

Fig. 3. Molecular structures of donor $\mathrm{CuPc}$ and acceptor PTCBI.

lowest unoccupied molecular orbital (LUMO) of the acceptor. If the off-sets of the energy levels of the donor and acceptor materials are higher than the exciton binding energy, photogenerated excitons in the donor side will dissociate by transferring the electron to the LUMO level of the acceptor, while those created in the other side will transfer the hole to the HOMO of the donor. Resulting free hole/electron charge carriers diffuse to the electrodes and are transported through semiconducting materials with the electron reaching the cathode $(\mathrm{Al})$ and the hole reaching the anode (ITO).

\section{Non-fullerenes acceptors for organic solar cells}

The first heterojunction OSC was reported by Tang where a 3,4,9,10-perylenetetracarboxylic bisbenzimidazole (PTCBI) (50 nm) as the acceptor and copper phthalocyanine $(\mathrm{CuPc})(30 \mathrm{~nm})$ as the donor were successively evaporated between ITO-coated glass substrate and Ag electrode (Fig. 3). The resulting bilayer device provided a PCE of $0.95 \%$, with a relatively high fill factor (FF) of $0.65\left(V_{\mathrm{oc}}=0.45 \mathrm{~V} ; J_{\mathrm{sc}}=2.3 \mathrm{~mA} \mathrm{~cm}^{-2}\right)$ under $75 \mathrm{~mW} \mathrm{~cm}^{-2}$ of AM2 illumination [10]. By modification of the device architecture with the same materials, efficiency exceeding $2 \%$ was attained $[21,22]$. It should be noted that the PTCBI acceptor is synthesized and used for devices as a mixture of cis and trans isomers. But the configuration cis/trans does not significantly interfere on the performance of the solar cell. Isomerically pure cis and trans PTCBI isomers were prepared by repeated fractionation in sulfuric acid. Bilayer devices consisting of $\mathrm{CuPc}$ and trans-, cis-, and mixed-PTCBI cells exhibited PCE of $1.1 \%, 0.93 \%$, and $0.99 \%$, respectively [23]. The higher efficiency for the trans isomer was attributed to a substantially better molecular ordering and a closer packing of trans-PTCBI molecules in corresponding films, mainly contributing to a higher exciton diffusion length.

Perylene-3,4:9,10-bis(dicarboximide) (PBI) derivatives are considered as the best n-type organic semiconductors available to date $[24,25]$. Because of their unique optical, redox, stability properties and charge carrier mobilities, PBI dyes provide significant prospects for investigations in photovoltaic devices [26]. Whereas solution processable perylene acceptors can be prepared by introducing 


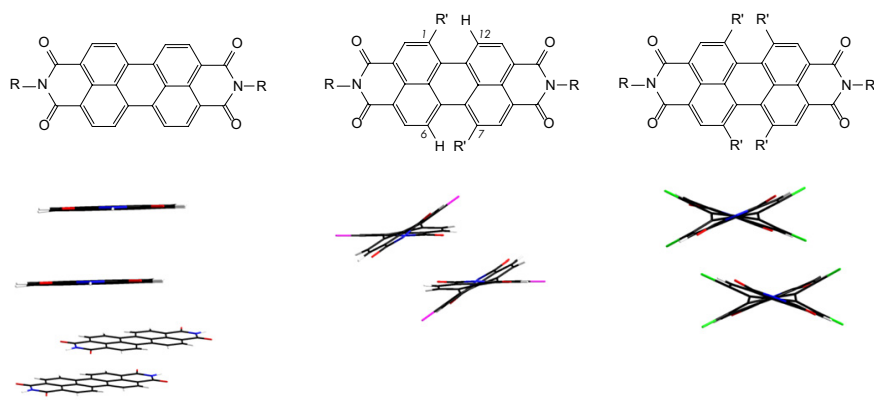

Fig. 4. Representation and X-ray crystallographic structures of planar non-bay substituted PBI (left) [30] and twisted diand tetrabay-substituted PBI derivatives.
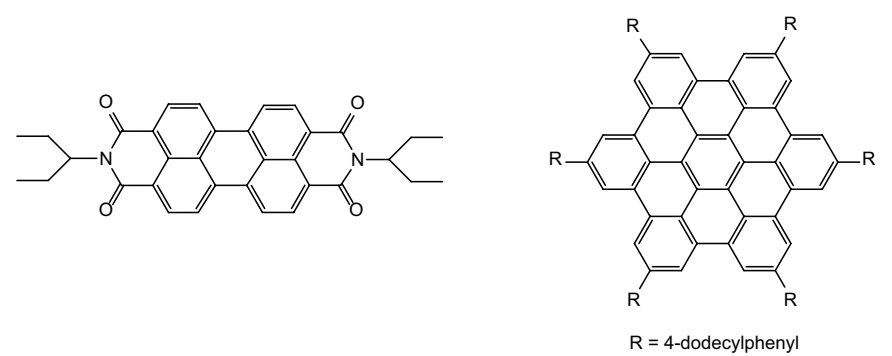

Fig. 5. Molecular structures of 2-ethylpropyl PBI and hexabenzocoronene (HBC).

solubilizing groups on the imide nitrogen atoms by keeping the planarity of the backbone, the synthesis of PBI derivatives bearing substituents in the 1,12- and 6,7-positions (the so-called bay region) has considerably promoted the development of emerging applications thanks to their increased solubility in organic solvents and the possibility to tune the electronic properties [24, 25, 27]. The introduction of substituents enforces a considerable twisting of the perylene skeleton as a result of electrostatic repulsion and steric effects among the substituents in positions 1,7 (31. $7^{\circ}$ for 1,7 -dibromoPBI) [28] or $1,6,7,12$ positions $\left(37^{\circ}\right.$ for 1,6,7,12-tetrachloroPBI) [29] (Fig. 4).

An interesting work was carried out on ethylpropylsubstituted PBI at the imide periphery which was blended with a variety of donor polymers using spin coating techniques to prepare photovoltaic devices. It was shown that the tendency of such PBI acceptor to form crystalline domains was limiting the efficiencies of devices by creation of electron traps thus reducing the photocurrent $[31,32]$. On the contrary, their high crystallinity could be exploited when this ethylpropyl-substituted PBI was blended with discotic liquid crystal alkylated hexabenzocoronene (HBC) (Fig. 5) [26,33,34]. An external quantum efficiency (EQE) of $34 \%$ corresponding to about $2 \%$ PCE was observed for the $\mathrm{PBI} / \mathrm{HBC}$ blend under illumination at $490 \mathrm{~nm}$.

Interesting results were recently reported with the device using the 1,7-bis(4-tert-butylphenoxy)-bay substituted PBI derivative containing pyrene moieties at the imide positions. This Pyrene-PBI-Pyrene triad acceptor was blended with a phenylenevinylene based oligomer playing the role of the donor (Fig. 6). The corresponding device using the donor/acceptor couple in a
1:3.5 ratio yielded a PCE of $1.87 \%\left(V_{\mathrm{oc}}=0.98 \mathrm{~V}\right.$, $\left.J_{\mathrm{sc}}=4.15 \mathrm{~mA} \mathrm{~cm}^{-2}, F F=0.46\right)$ which could reached $3.17 \%$ by insertion of a $\mathrm{ZnO}$ layer between the active organic layer and the cathode in order to enhance electron collection [35]. By introducing methylacenaphtho[1,2b]pyrazine-8,9-dicarbonitrile at the PBI periphery and benzo $[c][1,2,5]$-selenadiazole in the donor system, the device (ITO/PEDOT-PSS/Donor: Acceptor/Al) provided an efficiency of $3.88 \%\left(V_{\mathrm{oc}}=0.9 \mathrm{~V} ; J_{\mathrm{sc}}=8.30 \mathrm{~mA} \mathrm{~cm}^{-2}\right.$; $F F=0.52$ ). This performance was largely attributed to the wide 400-800 $\mathrm{nm}$ absorption range of the blend. This corresponds to the highest efficiency reported so far for a rylene-bisimide-based acceptor and also for a non-fullerene based organic BHJ solar cell [36].

Other classes of acceptors have been recently developed to be incorporated in OSCs. One of these corresponds to the diketopyrrolopyrrole (DPP) moiety. DPPbased polymers have recently received large attention for their excellent performance as donor materials in BHJ solar cells with an efficiency of $4.7 \%$ in combination with a fullerene derivative [37]. Interestingly the introduction of electron withdrawing groups such as fluoro or fluoroalkyl groups enhanced the DPP electron affinity to reach acceptor materials. For example, trifluoromethylphenyl groups have been introduced onto the DPP core and when blended in a BHJ device with the donor poly(3hexylthiophene) (P3HT), a PCE of $1.0 \%\left(V_{\mathrm{oc}}=0.81 \mathrm{~V}\right.$, $\left.J_{\mathrm{sc}}=2.36 \mathrm{~mA} \mathrm{~cm}^{-2}, F F=0.52\right)$ was achieved [38].

Similarly, metallophthalocyanines are widely known for their p-type conductivity but the introduction of fluorine atoms at the periphery of the aromatic rings increased their n-type character. A series of fluorinated boron subphthalocyanines used as acceptors in bilayer OSC devices were associated with phthalocyanine-based donors leading to PCE close to $1 \%$ [39]. Small molecular acceptors combining the highly electron deficient 2-vinyl4,5-dicyanoimidazole moiety named Vinazene and benzothiadiazole were developed as processable oligomers for photovoltaics applications [40]. These oligomers displayed a wide range of optical and electronic properties thanks to the modification of the central aromatic moiety. Best results were described by blending this bis-vinazene - benzothiadiazole oligomer with an octylphenyl-substituted polythiophene giving a device for which a PCE of $1.4 \%$ $\left(V_{\mathrm{oc}}=0.62 \mathrm{~V}, J_{\mathrm{sc}}=5.5 \mathrm{~mA} \mathrm{~cm}^{-2}, F F=0.4\right)$ could be obtained.

A recent innovative approach introduced the concept of gain of aromaticity as a driving force to reach efficient small molecule acceptors represented by the use of a 9,9'-bifluorenylidene $\left(99^{\prime} \mathrm{BF}\right)$ polycycle scaffold [41]. The addition of one electron onto the central double bond issued from the electron transfer from the donor should be highly favorable thanks to the formation of a less strained and twisted system which is characterized by a gain of aromaticity due to the generation of a 14- $\pi$ electron structure. Preliminary BHJ solar cells (ITO/PEDOT-PSS/P3HT: 99'BF/Ba/Al) showed an impressive $1.7 \%$ PCE, and a relatively high $V_{\mathrm{oc}}$ of $1.10 \mathrm{~V}$. Further promising results are expected in a near future 

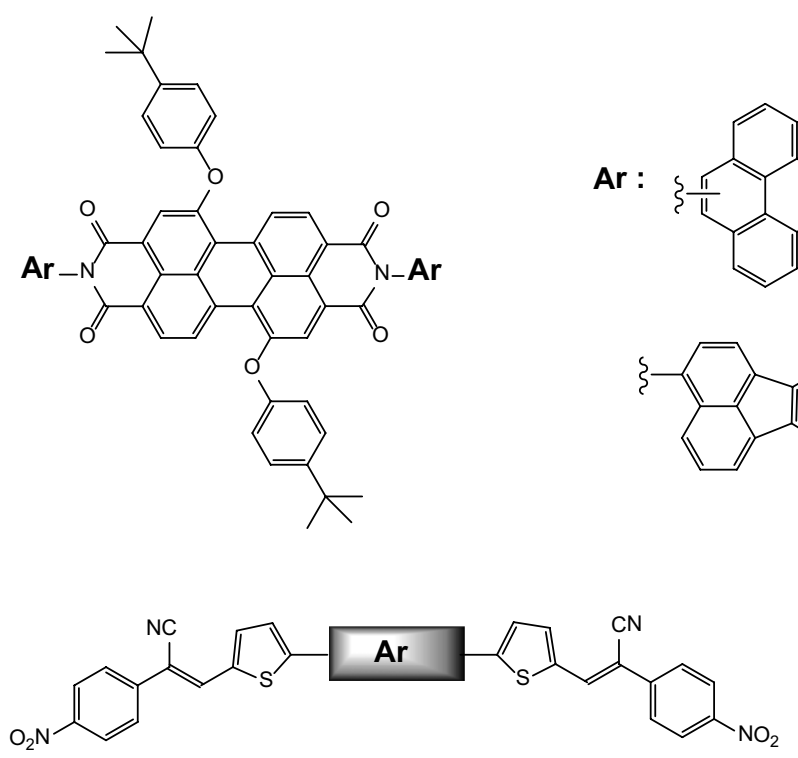

Ar:<smiles></smiles><smiles>N#Cc1nc2c(nc1C#N)-c1ccc(I)c3cccc-2c13</smiles>

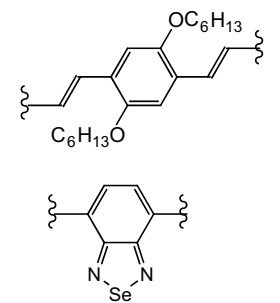

Fig. 6. Molecular structures of 1,7-bis(4-tert-butylphenoxy) bay-substituted PBI derivative acceptor and small-molecule based donor oligomer.

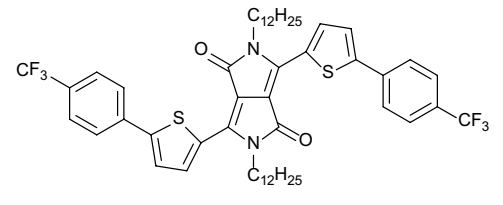

Diketopyrrolopyrrole (DPP)

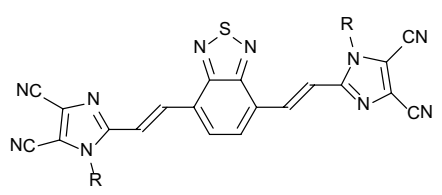

Vinazene-based oligomer
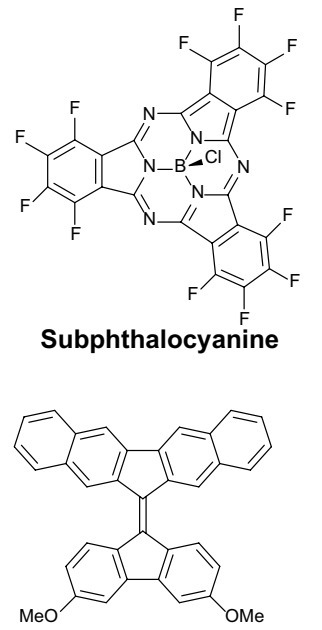

9,9'-Bifluorenylidene (99'BF)

Fig. 7. Molecular structures of other families developed as acceptors.

using this versatile 9,9'-bifluorenylidene backbone considering that the possibility of functionalization on theoretically twelve positions constitutes advantages of particular interest for the development by organic chemists of this scaffold.

\section{Fullerenes acceptors for organic solar cells}

It is clear that at the present time and in the field of organic photovoltaics, fullerene derivatives play a dominant role as acceptor materials. Main reasons for the choice of fullerenes are their favorable LUMO energy and reversible

reduction leading to stable reduced species, their excellent electron transport properties, and their spherical shape allowing a three-dimensional charge transport, perfectly in agreement with this of the three-dimensional hole transport ability of conjugated polymers. Nevertheless, to be applied in the fabrication process of OSCs, the functional fullerene requires sufficient solubility in organic solvents, such as toluene, chlorobenzene, or odichlorobenzene. With the aim of designing new efficient fullerene acceptors, it is important to have in mind some critical factors known to affect the performance of BHJ solar cells. First, the open circuit voltage $\left(V_{\mathrm{oc}}\right)$ was found to correlate directly with the acceptor strength of the fullerene derivative [42]. Moreover, in order to reach highest efficiencies, practically around $10 \%$, the difference between both LUMO levels of donor and acceptor needs to be around $0.3 \mathrm{eV}$ [43] (Fig. 8). Consequently, the energy level of the fullerene derivative has to be engineered to maximize the $\Delta E \operatorname{LUMO}(\mathrm{A})-\mathrm{HOMO}(\mathrm{D})$ to achieve high $V_{\text {oc }}$, while maintaining proper LUMO offset $[\Delta E$ LUMO(D) - LUMO(A)] to facilitate exciton dissociation. In a first approach, the $V_{\mathrm{oc}}$ was proposed to be proportional to the difference between the HOMO level of the donor and the LUMO level of the acceptor [7]. Then it was more precisely evidenced that the maximum attainable and empirical limit for the $V_{\mathrm{oc}}$ is equal to the optical band gap energy minus $\sim 0.60-0.66 \mathrm{~V}$ and that the $V_{\mathrm{oc}}$ correlates with the energy of the charge transfer states in donor-acceptor blend [44-46].

Soluble fullerene derivatives with the 6,6-phenyl$\mathrm{C}_{61}$-butyric acid methyl ester $([60] \mathrm{PCBM})$, historically synthesized by Hummelen et al. [47], and its $\mathrm{C}_{70}$ analogue $([70] \mathrm{PCBM})$ are the most widely used acceptors for BHJ solar cells. A major difference between $\mathrm{C}_{60}$ 


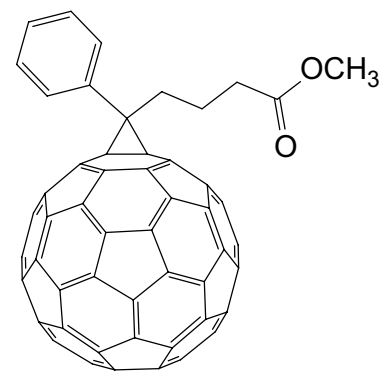

[60]PCBM

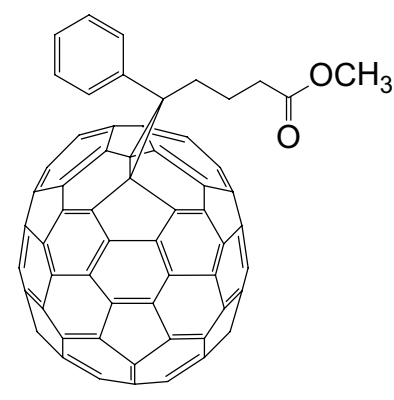

[70]PCBM

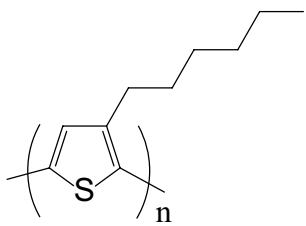

$\mathrm{P} 3 \mathrm{HT}$
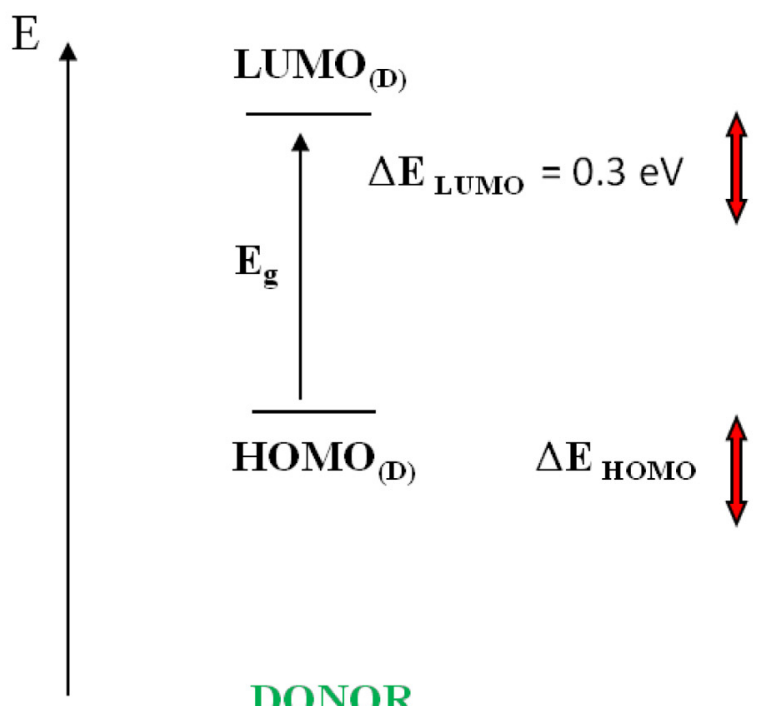

DONOR

ACCEPTOR

Fig. 8. Structures of PCBM molecules and schematic energy diagram with the bandgap energy $(E g)$ and the energy differences $(\Delta E)$ in a donor: [60]PCBM bulk-heterojunction.

and [60]PCBM concerns their relative acceptor strength, [60]PCBM appearing to be a less effective electron acceptor but more soluble in organic solvents than pristine $\mathrm{C}_{60}$. The LUMO of [60]PCBM was reported to be between $-3.7 \mathrm{eV}$ [48] and $-4.3 \mathrm{eV}$ [43] because of the different measurement techniques, either in solution or solid form, or with different standards to estimate the values. Recently, the LUMO and HOMO levels of fullerene acceptors measured under the same conditions were correlated using the PCBM reference molecule with its widely accepted LUMO $(-4.30 \mathrm{eV})$ and HOMO (-6.00 eV) energy levels [17]. Considering this LUMO value for [60]PCBM acceptor and if the bandgap of the polymer is in the range of $1.2-1.7 \mathrm{eV}$, this would correspond to donor HOMO levels of -5.2 to $-5.7 \mathrm{eV}$.

Since the advent of [60]PCBM, the blend which associated P3HT has been extensively investigated and exhibits a reproducible PCE around 5\% [49]. One drawback of fullerenes is their relatively low light absorption in the visible region of the spectrum. Although [70]PCBM partially solved this problem [50], a major breakthrough towards efficient organic devices was obtained with the development of low bandgap conjugated polymers able to harvest more light and to optimize corresponding energy levels to attain higher $V_{\mathrm{oc}}[51-53]$. When blended with [60]PCBM or [70]PCBM, efficiencies have increased up to $7-8 \%$ [54] with a record which has recently reached over $10 \%[13]$.

Nevertheless, due to the different energetic HOMO and LUMO levels to be respected, it clearly appeared that PCBM was not the best acceptor for solar cells containing near infrared absorbing polymers. Consequently, alternative fullerene materials have to be developed and efforts are currently being made by organic chemists to obtain alternatives to[60]PCBM and [70]PCBM acceptors [12].

In the last decade, synthetic efforts were strengthened for chemical engineering on PCBM to change the properties of the fullerene $\pi$-system and to design novel fullerene acceptors with higher-lying LUMO levels compared with PCBM (Fig. 9). A systematic study of slight variations on the aryl or alkyl groups of PCBM can cause a significant change in its physical properties and in particular its solubility in organic solvents with strong effects on the morphology of the blend and the efficiency of solar cells. 


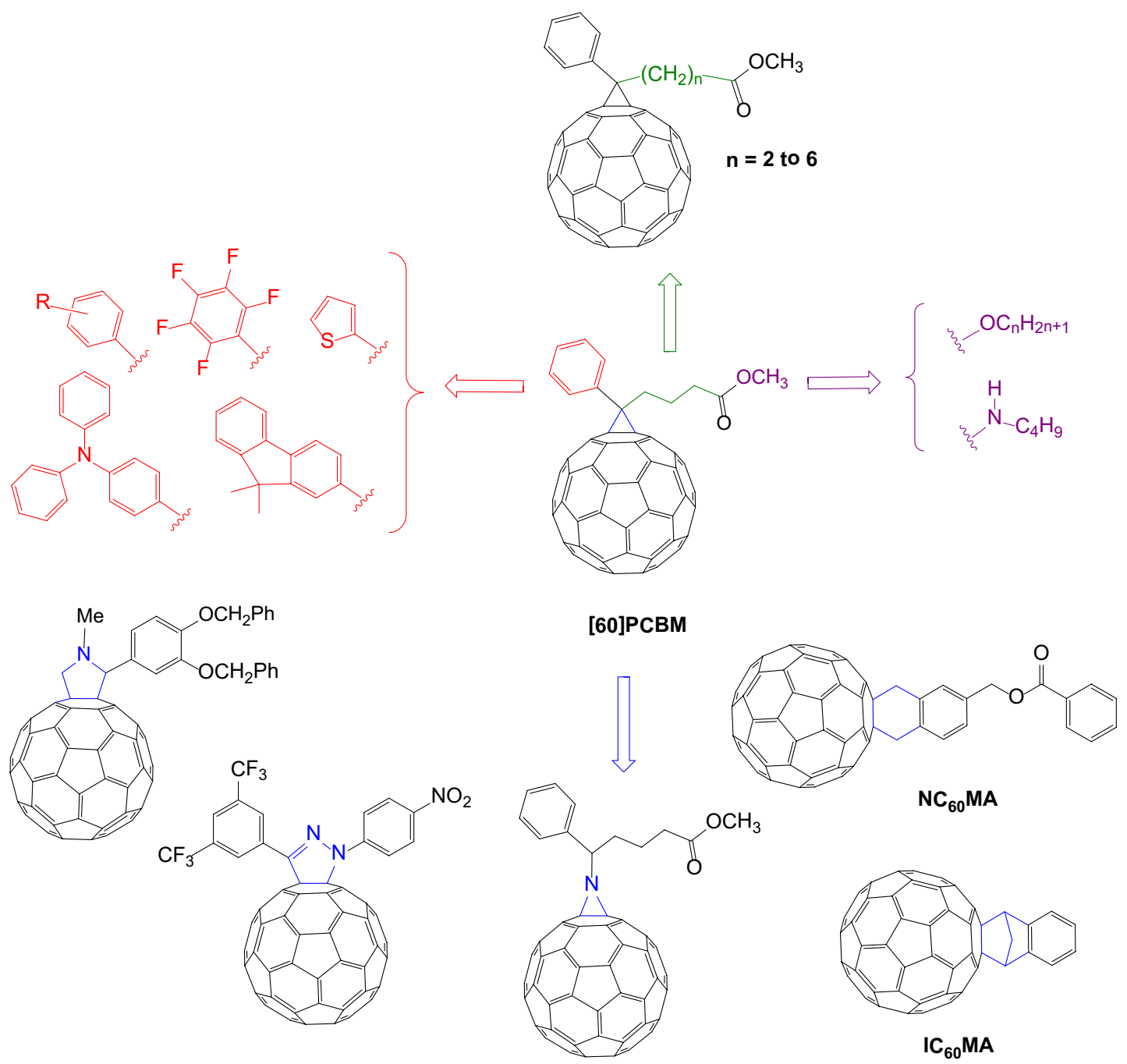

Fig. 9. An overview of modifications leading to $\mathrm{C}_{60}$ monoadducts.

It was concluded that the best combinations are those where donor and fullerene materials are of similar and sufficiently high solubility in the solvent used for the deposition of the active layer [55].

In order to evaluate the influence of electron-donating and -withdrawing groups on the electrochemical properties of [60]PCBM, the phenyl ring of [60]PCBM was substituted with different functional groups and fluorine atoms were shown to influence the most the first reduction potential [56]. On the other hand, the phenyl group of PCBM was replaced by a thienyl group [57] and the resulting BHJ solar cell based on P3HT: Th[60]CBM exhibited a PCE of $3.97 \%$ which was comparable to the reference P3HT: [60]PCBM device [58]. Another alternative consisted in replacing the phenyl ring with the bulky triphenylamine or 9,9-dimethylfluorene groups [59]. These acceptors showed electron mobility comparable to [60]PCBM, while solar cells using P3HT as the donor exhibited a high PCE of around $4 \%$ with a significant enhanced thermal stability thanks to the higher glasstransition temperature of these fullerene derivatives. Since a slight structural modification of PCBM can influence the photovoltaic performance significantly, a series of [60]PCBM-like fullerene derivatives were synthesized in which the alkyl chain in PCBM was changed from 3 to 7 carbon atoms [60]. Devices based on P3HT as the donor were fabricated and PCE varied from 2.3 to $3.7 \%$. These results indicated that the alkyl chain length significantly influenced the absorption intensity, the electron mobility, the morphology of the films, and the P3HT: PCBM analogue interface structure, so that it clearly influenced the photovoltaic performance of the solar cell. To enhance the solubility of [60]PCBM in organic solvents, several analogues were synthesized with different ester alkyl chains, varying from $\mathrm{C}_{1}$ to $\mathrm{C}_{16}[61,62]$. The length of the chain did not influence optical and electrochemical properties but it was noted that the morphology of the film was improved with length and the more soluble acceptors were able to produce a good quality film either alone or as a blend with donor components. The effect of the chain length on the terminal ester functionality was also established [63] as well as the replacement of the ester group by an acid 


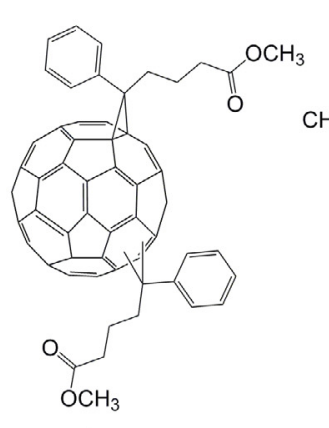

[60]PCBM bis-adduct
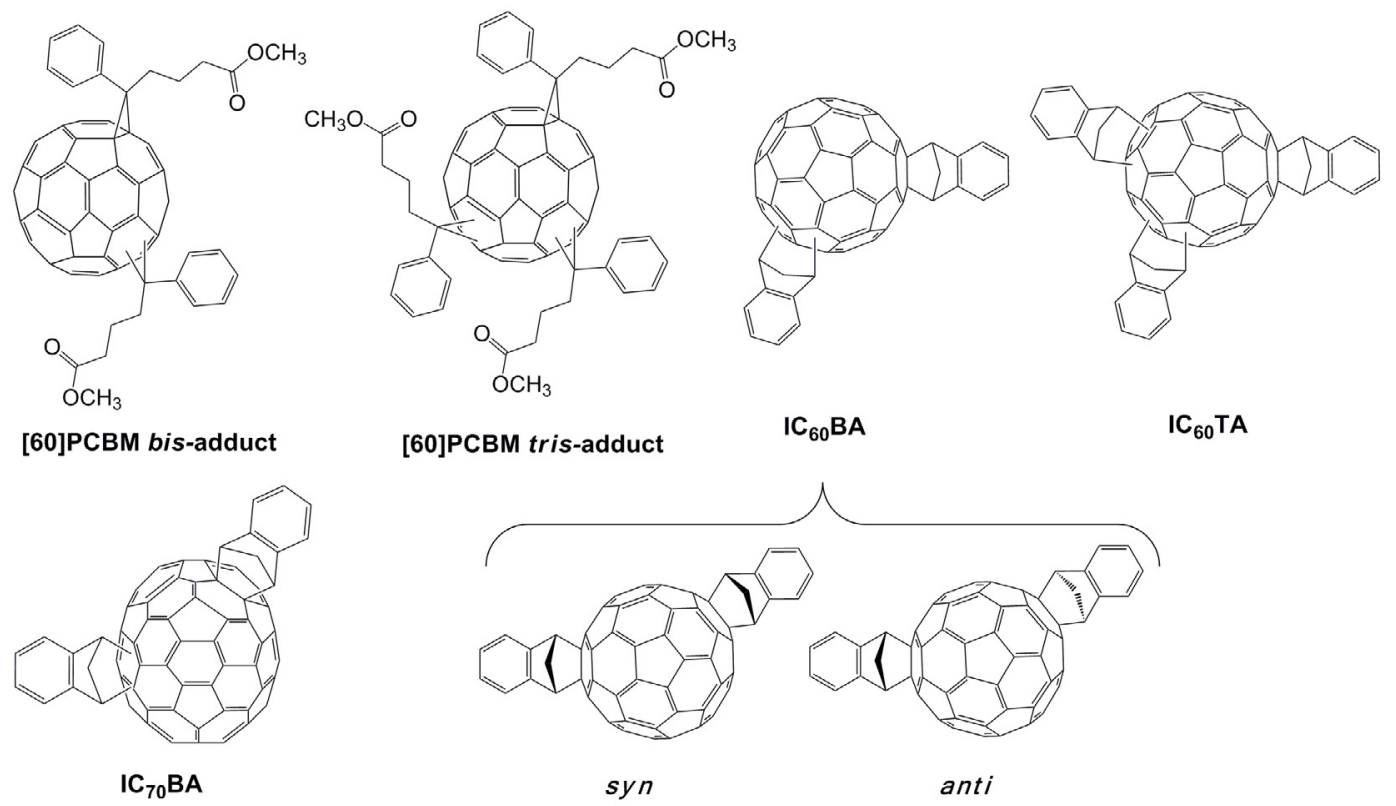

[60]PCBM tris-adduct

$\mathrm{IC}_{60} \mathrm{BA}$

$\mathrm{IC}_{60} \mathrm{TA}$

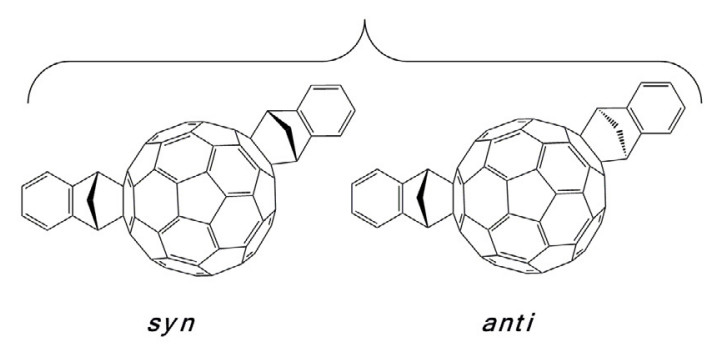

Fig. 10. Molecular structures of bis- and tris-adducts currently used in OSCs.

or amide functionality in order to evaluate the role of hydrogen bonds in the aggregation of fullerenes [64,65]. Among the different strategies investigated for modification of the attachment mode on the fullerene moiety using cycloaddition reaction [66-70] (Fig. 9), new soluble fullerene derivatives were synthesized using the $[4+2]$ Diels-Alder reaction onto $\mathrm{C}_{60}$ [71] to reach $\mathrm{IC}_{60} \mathrm{MA}$ [72] and $\mathrm{NC}_{60} \mathrm{MA}$ cycloadducts [73]. Blends P3HT: $\mathrm{NC}_{60} \mathrm{MA}$ were fabricated which exhibited a PCE up to $4.5 \%\left(V_{\mathrm{oc}}=\right.$ $0.65 \mathrm{~V}, J_{\mathrm{sc}}=11.3 \mathrm{mAcm}^{-2}, F F=0.57$, AM 1.5 G $80-100 \mathrm{~mW} \mathrm{~cm}^{-2}$ ). This suggested that excellent alternatives to PCBM could be reasonably considered in the future.

The maximum $V_{\text {oc }}$ delivered by the BHJ in polymer: fullerene solar cells being correlated to the difference between the energy of the HOMO of the donor and the LUMO of the acceptor, some research works have focused on the strategy to design fullerene $\mathrm{C}_{60}$ bis-adducts raising directly the LUMO energy level with an increase of the $V_{\text {oc }}$ (Fig. 10). An increase of about $100 \mathrm{meV}$ for the bis [60]PCBM LUMO level was reported [74], and the corresponding $\mathrm{P} 3 \mathrm{HT}$ : bis[60]PCBM device exhibited a $\mathrm{PCE}$ of $4.5 \%\left(V_{\mathrm{oc}}=0.72 \mathrm{~V}, J_{\mathrm{sc}}=0.91 \mathrm{~mA} \mathrm{~cm}^{-2}, F F=0.68\right.$, AM $1.5 \mathrm{G} 100 \mathrm{~mW} \mathrm{~cm}^{-2}$ ), this being 1.2 larger than that of similar P3HT: [60]PCBM solar cells. Consequently, the bis-adduct isomer mixture could be used without further separation of the theoretically eight regioisomers to yield enhanced cell performance compared to that of [60]PCBM.

A remarkable indene- $\mathrm{C}_{60}$ bis-adduct $\left(\mathrm{IC}_{60} \mathrm{BA}\right)$ was more recently invented in 2006 by Laird et al. (Plextronics \& NanoC patent) using a Diels-Alder cycloaddition of indene to $\mathrm{C}_{60}$ as a mixture of multiple isomers, considering that two syn and anti configurations could exist for each regioisomer [75]. The $\mathrm{IC}_{60} \mathrm{BA}$ acceptor is characterized by a LUMO energy level $0.17 \mathrm{~V}$ higher than that of [60]PCBM [76]. The solar cell based on P3HT: $\mathrm{IC}_{60} \mathrm{BA}$ showed a high $V_{\mathrm{oc}}$ of $0.84 \mathrm{~V}$ and an impressive PCE of $5.1 \%\left(V_{\mathrm{oc}}=0.84 \mathrm{~V}, J_{\mathrm{sc}}=9.43 \mathrm{mAcm}^{-2}\right.$, $F F=0.64$, AM $1.5 \mathrm{G} 100 \mathrm{~mW} \mathrm{~cm}^{-2}$ ) [75] or $5.44 \%$ $\left(V_{\mathrm{oc}}=0.84 \mathrm{~V}, J_{\mathrm{sc}}=9.7 \mathrm{~mA} \mathrm{~cm}^{-2}, F F=0.67, \mathrm{AM}\right.$

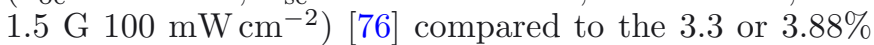
for a reference solar cell based on [60]PCBM, respectively. After optimization of the device morphology, a PCE of $6.48 \%$ was achieved $\left(V_{\mathrm{oc}}=0.84 \mathrm{~V}, J_{\mathrm{sc}}=10.61 \mathrm{~mA} \mathrm{~cm}^{-2}\right.$, $F F=0.73$, AM $1.5 \mathrm{G} 100 \mathrm{~mW} \mathrm{~cm}^{-2}$ ) as the highest values reported in the literature so far for P3HT-based solar cells [77]. Reproducibility on twenty P3HT: $\mathrm{IC}_{60} \mathrm{BA}$ devices from 6.06 to $6.76 \%$ indicated that the photovoltaic performance of ICBA as acceptor is greatly superior to that of the traditional [60]PCBM with a PCE of $3.73 \%$ obtained in the same experimental conditions. An efficient way to improve OSCs efficiency consists in using the tandem structure in order to cover a broad part of the emission solar spectrum. By combining P3HT: $\mathrm{IC}_{60} \mathrm{BA}$ in a front cell and PDTB-DFBT: [60]PCBM in a rear cell, with PDTB-DFBT acting as a benzothiadiazole based low bandgap polymer, a certified $10.6 \%$ PCE was very recently attained $\left(V_{\mathrm{oc}}=1.53 \mathrm{~V}, J_{\mathrm{sc}}=10.1 \mathrm{~mA} \mathrm{~cm}^{-2}, F F=0.68\right.$,

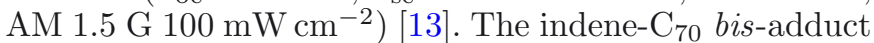
$\left(\mathrm{IC}_{70} \mathrm{BA}\right)$ analogue was synthesized and the LUMO energy level of $\mathrm{IC}_{70} \mathrm{BA}$ was shown to be $0.19 \mathrm{eV}$ higher than that of [70]PCBM [78]. P3HT: $\mathrm{IC}_{70} \mathrm{BA}$ devices showed a higher $V_{\mathrm{oc}}$ of $0.84 \mathrm{~V}$ and higher PCE of $5.64 \%$, while the devices based on P3HT: [60]PCBM $\left(V_{\mathrm{oc}}=0.59 \mathrm{~V}\right)$ and P3HT: $[70] \mathrm{PCBM}\left(V_{\mathrm{oc}}=0.58 \mathrm{~V}\right)$ blends displayed PCE of $3.55 \%$ and $3.96 \%$, respectively.

Nevertheless, a limiting factor to this polymer: $\mathrm{C}_{60}$ bisadducts strategy was evidenced for some blends where a simultaneous dramatic loss in the $J_{\mathrm{sc}}$ and lower electron mobilities resulted in a reduced PCE for most polymers other than P3HT [79]. It was identified that the principal 

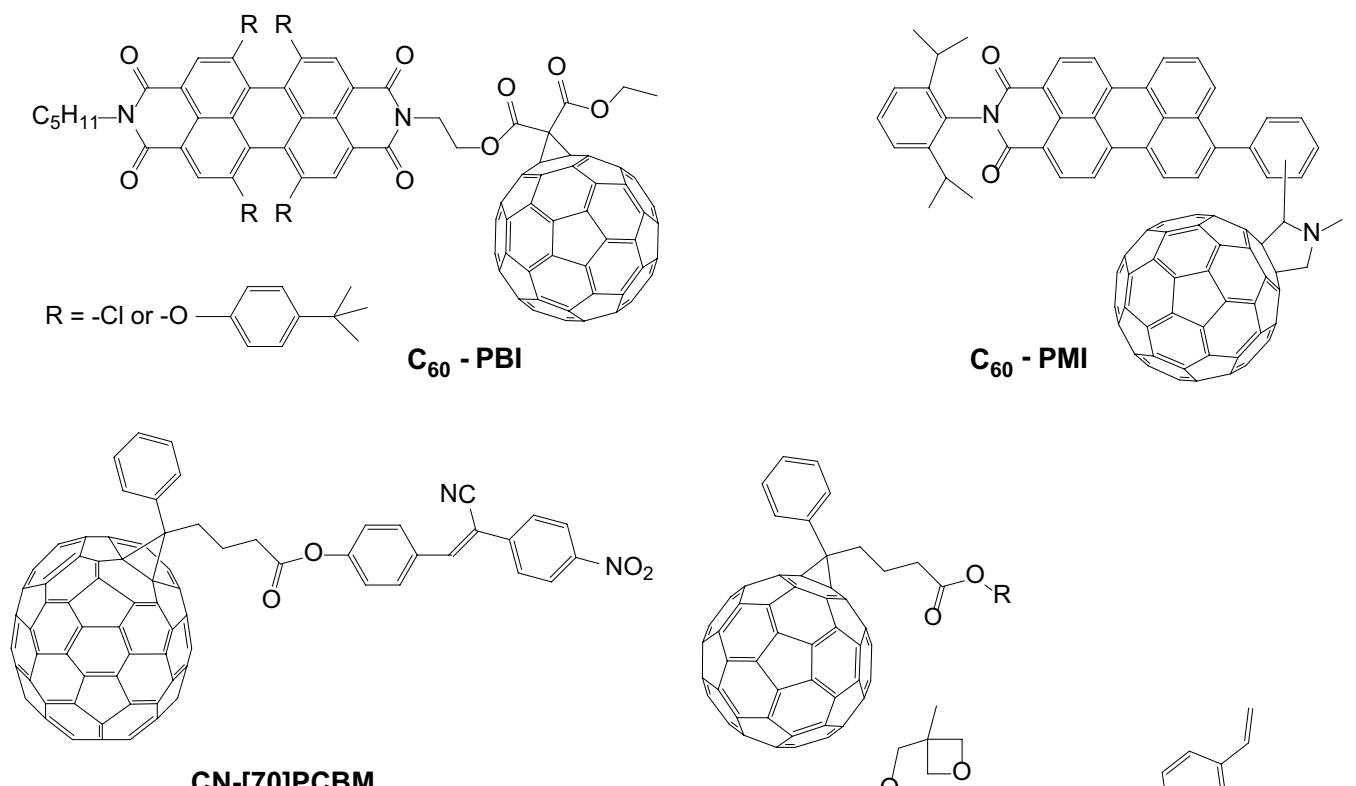

$\mathrm{CN}-[70] \mathrm{PCBM}$
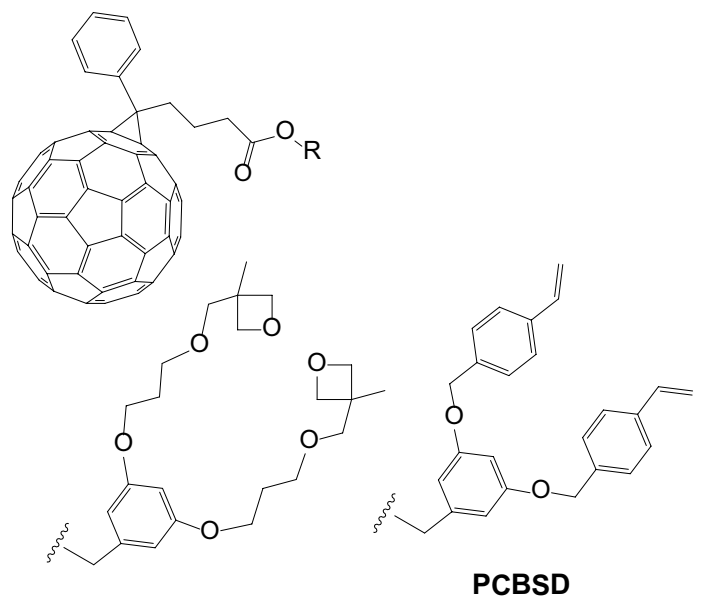

Fig. 11. Examples of highly absorbing and cross-linkable fullerenes for applications in OSCs.

reason was the correlation between $J_{\mathrm{sc}}$ and the free energy of the photoinduced charge generation $\Delta G_{\mathrm{CT}}$. An increase of this parameter $\Delta G_{\mathrm{CT}}$ was shown to eventually inhibit the photoinduced electron transfer between the polymer and the fullerene bis-adduct [80].

In addition to the systematic decrease of the electron affinity of the acceptor with the number of additions onto the fullerene moiety, it was shown that the introduction of a third unit impacts all device parameters and performance. For example, the blend P3HT: [60]PCBM trisadduct, although having a high $V_{\text {oc }}$ of $0.81 \mathrm{~V}$, showed significantly reduced efficiency due to the deterioration of electron transport in the fullerene phase [81]. In the indene series, the $V_{\text {oc }}$ values increase effectively with the degree of substitution for BHJ solar cells fabricated with P3HT (0.65, 0.83 and $0.92 \mathrm{~V}$ for $\mathrm{IC}_{60} \mathrm{MA}, \mathrm{IC}_{60} \mathrm{BA}$ and $\mathrm{IC}_{60} \mathrm{TA}$, respectively), but the P3HT: ICTA based device exhibited a much lower efficiency (1.56\%) compared with similar device P3HT: ICBA (5.26\%) [82]. It was suggested that an increase of the number of solubilizing groups added to the $\mathrm{C}_{60}$ decreased the electron mobility due to significant structural disorder and hindered electron transport within the fullerene phase resulting in lower current and fill factor [83].

Innovative approaches need to be applied for OSCs to cover the visible and near infrared region of the solar spectrum. One route, as an alternative strategy to the development of low bandgap polymers, consists in the improvement of the light-harvesting ability of the fullerene derivatives. The principle of associating a dye attached to the fullerene was proposed to reach $\mathrm{C}_{60}-\mathrm{PBI}$ or $\mathrm{C}_{60}-\mathrm{PMI}$ dyads as super-absorbing fullerenes (Fig. 11) [84-87]. Even if the PCE were low using this dyad as an acceptor, the role of the perylenebisimide (PBI) acting as a light-harvesting antenna was evidenced by an efficient intramolecular energy transfer occurring from $\mathrm{PBI}$ onto $\mathrm{C}_{60}$ and the relationship between electrochemical properties of the dyad and the P3HT: $\mathrm{C}_{60}-\mathrm{PBI}$ blend efficiency was evidenced [88]. Another efficient example was recently reported by modification of [70]PCBM with introduction of a cyanovinylene 4-nitrophenyl moiety. Resulting CN[70]PCBM showed broader and stronger absorption in the visible region $(350-550 \mathrm{~nm})$ of the solar spectrum. The P3HT: CN-[70]PCBM blend showed a PCE of $4.88 \%$, which is higher than that of devices based on [70]PCBM as the electron acceptor $(3.23 \%)$. An increase in both the $J_{\mathrm{sc}}$ and the $V_{\mathrm{oc}}$ were noted thanks to the stronger light absorption of CN-[70]PCBM and a LUMO level higher by $0.15 \mathrm{eV}$ compared to that of [70]PCBM [89].

Among aspects other than efficiency, improved processing, cost, and stability have been identified as important for the future development of OSCs [90]. It remains highly challenging to develop such devices that can provide a high PCE while maintaining good ambient stability, since prolonged exposure to air rapidly reduces the performance of unencapsulated conventional devices. The incorporation of an additional n-type $\mathrm{C}_{60}$ derivative as an interlayer or in the organic active layer might improve the device performance and the long-term stability thanks to the establishment of a thermal chemical 
P. Hudhomme: An overview of molecular acceptors for organic solar cells

cross-linking process. In this topic, main results involved the synthesis of cross-linkable fullerene materials for which epoxyde [91], oxetane [92], or styryl groups have been introduced (Fig. 11). In the latter case, the[60]PCB styryl dendron ester (PCBSD) was incorporated as an interlayer in P3HT: [60]PCBM [93] or P3HT: $\mathrm{IC}_{60} \mathrm{BA}$ [94] solar cells. Whereas the P3HT: $\mathrm{IC}_{60} \mathrm{BA}$ inverted device was leading to a remarkable PCE of $4.8 \%$, the incorporation of PCBSD yielded to an exceptional record PCE of $6.2 \%$ then $7.3 \%$ using cross-linked-PCBSD nanorods [95].

\section{Conclusion}

Organic solar cells have shown a tremendous progress over the past decade with an important increase in the power coefficient efficiency. In parallel to the redaction of this mini-review, an accredited new record with $12 \%$ efficiency was achieved by Heliatek industry for organic photovoltaics $^{1}$. Moreover, the estimation of the efficiency limits was very recently revisited and theoretical models suggested that $20-24 \%$ could be attained in organic photovoltaics [96]. Research efforts have been dominated by the optimization of the materials by tuning their optical and electronic properties, the design and the control of nanoscale morphology of devices. Whereas the synthesis of p-type donor materials was particularly fruitful, n-type acceptors have been less regarded. Non-fullerene based acceptors are today gaining attention and the new challenge for them would be to attain in the near future the efficiency of fullerene derivatives for which PCBM and more recently $\mathrm{ICBA}$ are leaders. Whereas $\mathrm{C}_{60}$ was regarded two decades ago as an exotic material, costs have been dramatically reduced (20\$ per gram in 2013!) and their derivatives are now compatible for an industrial application in organic photovoltaics. In searching for the next generation of fullerene acceptors, some efforts should be directed to derivatives which possess a broader absorption coverage with high extinction coefficient, a controlled LUMO level to achieve the highest $V_{\mathrm{oc}}$, a high electron mobility, and the development of derivatives which do not aggregate should also increase the stability of the device. Chemical and technological challenges will have to be overcome, but there is undoubtedly an exciting future for organic chemists to offer new acceptors for the development of organic photovoltaics.

The author acknowledges funding from the Agence Nationale de la Recherche (ANR) for financial support to the HABISOL 2010-003 (PROGELEC) program CEPHORCAS.

\section{References}

1. B. O'Regan, M. Grätzel, Nature 336, 737 (1991)

2. M. Grätzel, Nature 414, 338 (2001)

3. M. Grätzel, Acc. Chem. Res. 42, 1788 (2009)

\footnotetext{
1 http://www.heliatek.com/
}

4. A. Hagfeldt, G. Boschloo, L. Sun, L. Kloo, H. Pettersson, Chem. Rev. 110, 6595 (2010)

5. S. Günes, H. Neugebauer, N.S. Sariciftci, Chem. Rev. 107, 1324 (2007)

6. B.C. Thompson, J.M.J. Fréchet, Angew. Chem. Int. Ed. 47, 58 (2008)

7. G. Dennler, M.C. Scharber, C.J. Brabec, Adv. Mater. 21, 1323 (2009)

8. R. Po, M. Maggini, N. Camaioni, J. Phys. Chem. C 114, 695 (2010)

9. C.J. Brabec, S. Gowrisanker, J.J.M. Halls, D. Laird, S. Jia, S.P. Williams, Adv. Mater. 22, 3839 (2010)

10. C.W. Tang, Appl. Phys. Lett. 48, 183 (1986)

11. N.S. Sariciftci, L. Smilowitz, A.J. Heeger, F. Wudl, Science 258, 1474 (1992)

12. F.G. Brunetti, R. Kumar, F. Wudl, J. Mater. Chem. 20, $2934(2010)$

13. J. You, L. Dou, K. Yoshimura, T. Kato, K. Ohya, T. Moriarty, K. Emery, C.C. Chen, J. Gao, G. Li, Y. Yang, Nat. Commun. 4, 1446 (2013)

14. P. Sonar, J.P.F. Lim, K.L. Chan, Energy Environ. Sci. 4, 1558 (2011)

15. J.E. Anthony, Chem. Mater. 23, 583 (2011)

16. P. Hudhomme, J. Cousseau, in Fullerenes, principles and applications, edited by F. Langa, J.-F. Nierengarten, 2nd edn. (RSC Publishing, 2011), Vol. 12, p. 416

17. C.-Z. Li, H.-L. Yip, A.K.-Y. Jen, J. Mater. Chem. 22, 4161 (2012)

18. T. Ameri, G. Dennler, C. Lungenschmied, C.J. Brabec, Energy Environ. Sci. 2, 347 (2009)

19. A. Mishra, P. Bäuerle, Angew. Chem. Int. Ed. 51, 2020 (2012)

20. J.-L. Brédas, J.E. Norton, J. Cornil, V. Coropceanu, Acc. Chem. Res. 42, 1691 (2009)

21. P. Peumans, V. Bulovic, S.R. Forrest, Appl. Phys. Lett. 76, $2650(2000)$

22. A. Yakimov, S.R. Forrest, Appl. Phys. Lett. 80, 1667 (2002)

23. S.B. Rim, R.F. Fink, J.C. Schöneboom, P. Erk, P. Peumans, Appl. Phys. Lett. 91, 173504 (2007)

24. F. Würthner, Chem. Commun., 1564 (2004)

25. C. Huang, S. Barlow, S.R. Marder, J. Org. Chem. 76, 2386 (2011)

26. L. Schmidt-Mende, A. Fechtenkotter, K. Müllen, E. Moons, R.H. Friend, J.D. MacKenzie, Science 293, 1119 (2001)

27. L. Perrin, P. Hudhomme, Eur. J. Org. Chem. 28, 5427 (2011)

28. P. Rajasingh, R. Cohen, E. Shirman, L.J.W. Shimon, B. Rybtchinski, J. Org. Chem. 72, 5973 (2007)

29. S. Leroy-Lhez, J. Baffreau, L. Perrin, E. Levillain, M. Allain, M.-J. Blesa, P. Hudhomme, J. Org. Chem. 70, 6313 (2005)

30. O. Guillermet, M. Mossoyan-Deneux, M. Giorgi, A. Glachant, J.C. Mossoyan, Thin Solid Films 514, 25 (2006)

31. J.J. Dittmer, R. Lazzaroni, P. Leclère, P. Moretti, M. Granstrom, K. Petritsch, E.A. Marseglia, R.H. Friend, J.L. Brédas, H. Rost, A.B. Holmes, Sol. Energy Mater. Sol. Cells 61, 53 (2000)

32. J.J. Dittmer, E.A. Marseglia, R.H. Friend, Adv. Mater. 12, $1270(2000)$

33. J. Li, M. Kastler, W. Pisula, J.W.F. Robertson, D. Wasserfallen, A.C. Grimsdale, J. Wu, K. Müllen, Adv. Funct. Mater. 17, 2528 (2007) 
34. G. De Luca, A. Liscio, M. Melucci, T. Schnitzler, W. Pisula, C.G. Clark, L.M. Scolaro, V. Palermo, K. Müllen, P. Samori, J. Mater. Chem. 20, 71 (2010)

35. G.D. Sharma, P. Suresh, J.A. Mikroyannidis, M.M. Stylianakis, J. Mater. Chem. 20, 561 (2010)

36. G.D. Sharma, P. Balraju, J.A. Mikroyannidis, M.M. Stylianakis, Synth. Met. 160, 932 (2010)

37. J.C. Bijleveld, A.P. Zoombelt, S.G.J. Mathijssen, M.M. Wienk, M. Turbiez, D.M. de Leeuw, R.A.J. Janssen, J. Am. Chem. Soc. 131, 16616 (2009)

38. P. Sonar, G.M. Ng, T.T. Lin, A. Dodabalapur, Z.K. Chen, J. Mater. Chem. 20, 3626 (2010)

39. H. Gommans, T. Aernouts, B. Verreet, P. Heremans, A. Medina, C.G. Claessens, T. Torres, Adv. Funct. Mater. 19, 3435 (2009)

40. C.H. Woo, T.W. Holcombe, D.A. Unruh, A. Sellinger, J.M.J. Fréchet, Chem. Mater. 22, 1673 (2010)

41. F.G. Brunetti, X. Gong, M. Tong, A.J. Heeger, F. Wudl, Angew. Chem. Int. Ed. 49, 532 (2010)

42. C.J. Brabec, A. Cravino, D. Meissner, N.S. Sariciftci, T. Fromherz, M.T. Rispens, L. Sanchez, J.C. Hummelen, Adv. Funct. Mater. 11, 374 (2001)

43. M.C. Scharber, D. Mühlbacher, M. Koppe, P. Denk, C. Waldauf, A.J. Heeger, C.J. Brabec, Adv. Mater. 18, 789 (2006)

44. D. Veldman, S.C.J. Meskers, R.A.J. Janssen, Adv. Funct. Mater. 19, 1939 (2009)

45. K. Vandewal, K. Tvingstedt, A. Gadisa, O. Inganäs, J.V. Manca, Nat. Mater. 8, 904 (2009)

46. M.A. Faist, T. Kirchartz, W. Gong, R.S. Ashraf, I. McCulloch, J.C. de Mello, N.J. Ekins-Daukes, D.D.C. Bradley, J. Nelson, J. Am. Chem. Soc. 134, 685 (2012)

47. J.C. Hummelen, B.W. Knight, F. Lepeq, F. Wudl, J. Yao, C.L. Wilkins, J. Org. Chem. 60, 532 (1995)

48. J.J. Benson-Smith, L. Goris, K. Vandewal, K. Haenen, J.V. Manca, D. Vanderzande, D.D.C. Bradley, J. Nelson, Adv. Funct. Mater. 17, 451 (2007)

49. M.T. Dang, L. Hirsch, G. Wantz, Adv. Mater. 23, 3597 (2011)

50. J.M. Kroon, M.M. Wienk, W.J.H. Verhees, J. Knol, J.C. Hummelen, P.A. van Hal, R.A.J. Janssen, Angew. Chem. Int. Ed. 42, 3371 (2003)

51. Y.-J. Cheng, S.-H.Yang, C.-S. Hsu, Chem. Rev. 109, 5868 (2009)

52. J. Chen, Y. Cao, Acc. Chem. Res. 42, 1709 (2009)

53. H. Zhou, L. Yang, W. You, Macromolecules 45, 607 (2012)

54. Y. Liang, Z. Xu, J. Xia, S.-T. Tsai, Y. Wu, G. Li, C. Ray, L. Yu, Adv. Mater. 22, E135 (2010)

55. P.A. Troshin, H. Hoppe, J. Renz, M. Egginger, J.Y. Mayorova, A.E. Goryachev, A.S. Peregudov, R.N Lyubovskaya, G. Gobsch, N.S. Sariciftci, V.F. Razumov, Adv. Funct. Mater. 19, 779 (2009)

56. F.B. Kooistra, J. Knol, F. Kastenberg, L.M. Popescu, W.J.H. Verhees, J.M. Kroon, J.C. Hummelen, Org. Lett. 9, 551 (2007)

57. L.M. Popescu, P. van't Hof, A.B. Sieval, H.T. Jonkman, J.C. Hummelen, Appl. Phys. Lett. 89, 213507 (2006)

58. J.H. Choi, K.-I. Son, T. Kim, K. Kim, K. Ohkubo, S. Fukuzumi, J. Mater. Chem. 20, 475 (2010)

59. Y. Zhang, H.-L. Yip, O. Acton, S.K. Hau, F. Huang, A.K.-Y. Jen, Chem. Mater. 21, 2598 (2009)

60. G. Zhao, Y. He, Z. Xu, J. Hou, M. Zhang, J. Min, H.-Y. Chen, M. Ye, Z. Hong, Y. Yang, Y. Li, Adv. Funct. Mater. 20, $1480(2010)$
61. L. Zheng, Q. Zhou, X. Deng, M. Yuan, G. Yu, Y. Cao, J. Phys. Chem. B 108, 11921 (2004)

62. C.-H. Yang, J.-Y. Chang, P.-H. Yeh, T.-F. Guo, Carbon 45, 2951 (2007)

63. L. Zheng, Q. Zhou, X. Deng, W. Fei, N. Bin, Z.-X. Guo, G. Yu, Y. Cao, Thin Solid Films 489, 251 (2005)

64. C. Yang, J.Y. Kim, S. Cho, J.K. Lee, A.J. Heeger, F. Wudl, J. Am. Chem. Soc. 130, 6444 (2008)

65. C. Liu, Y. Li, C. Li, W. Li, C. Zhou, H. Liu, Z. Bo, Y. Li, J. Phys. Chem. C 113, 21970 (2009)

66. N. Camaioni, L. Garlaschelli, A. Geri, M. Maggini, G. Possamai, G. Ridolfi, J. Mater. Chem. 12, 2065 (2002)

67. N. Camaioni, G. Ridolfi, G. Casalbore-Miceli, G. Possamai, L. Garlaschelli, M. Maggini, Sol. Energy Mater. Sol. Cells 76, 107 (2003)

68. X. Wang, E. Perzon, J.L. Delgado, P. de la Cruz, F. Zhang, F. Langa, M. Andersson, O. Inganäs, Appl. Phys. Lett. 85, $5081(2004)$

69. X. Wang, E. Perzon, F. Oswald, F. Langa, S. Admassie, M.R. Andersson, O. Inganäs, Adv. Funct. Mater. 15, 1665 (2005)

70. S.K. Pal, T. Kesti, M. Maiti, F. Zhang, O. Inganäs, S. Hellström, M.R. Andersson, F. Oswald, F. Langa, T. Österman, T. Pascher, A. Yartsev, V. Sundström, J. Am. Chem. Soc. 132, 12440 (2010)

71. P. Hudhomme, C.R. Chim. 9, 881 (2006)

72. A. Puplovskis, J. Kacens, O. Neilands, Tetrahedron Lett. 38, 285 (1997)

73. S.A. Backer, K. Sivula, D.F. Kavulak, J.M.J. Fréchet, Chem. Mater. 19, 2927 (2007)

74. M. Lenes, G.A.H. Wetzelaer, F.B. Kooistra, S.C. Veenstra, J.C. Hummelen, P.W.M. Blom, Adv. Mater. 20, 2116 (2008)

75. D.W. Laird, R. Stegamat, H. Richter, V. Vejins, L. Scott, T.A. Lada, Patent US 8, 217, 260

76. Y. He, H.-Y. Chen, J. Hou, Y. Li, J. Am. Chem. Soc. 132, $1377(2010)$

77. G. Zhao, Y. He, Y. Li, Adv. Mater. 22, 4355 (2010)

78. Y. He, G. Zhao, B. Peng, Y. Li, Adv. Funct. Mater. 20, $3383(2010)$

79. M.A. Faist, S. Shoaee, S. Tuladhar, G.F.A. Dibb, S. Foster, W. Gong, T. Kirchartz, D.D.C. Bradley, J.R. Durrant, J. Nelson, Adv. Energy Mater. (2013), DOI: 10.1002/aenm. 201200673

80. D.Di Nuzzo, G.-J.A.H. Wetzelaer, R.K.M. Bouwer, V.S. Gevaerts, S.C.J. Meskers, J.C. Hummelen, P.W.M. Blom, R.A.J. Janssen, Adv. Energy Mater. 3, 85 (2013)

81. M. Lenes, S.W. Shelton, A.B. Sieval, D.F. Kronholm, J.C. Hummelen, P.W.M. Blom, Adv. Funct. Mater. 19, 3002 (2009)

82. H. Kang, C.-H. Cho, H.-H. Cho, T.E. Kang, H.J. Kim, K.-H. Kim, S.C. Yoon, B.J. Kim, Appl. Mater. Interfaces 4, 110 (2012)

83. A.M. Nardes, A.J. Ferguson, J.B. Whitaker, B.W. Larson, R.E. Larsen, K. Maturová, P.A. Graf, O.V. Boltalina, S.H. Strauss, N. Kopidakis, Adv. Funct. Mater. 22, 4115 (2012)

84. J. Baffreau, L. Perrin, S. Leroy-Lhez, P. Hudhomme, Tetrahedron Lett. 46, 4599 (2005)

85. J. Baffreau, S. Leroy-Lhez, P. Hudhomme, M.M. Groeneveld, I.H.M. van Stokkum, R.M. Williams, J. Phys. Chem. A 110, 13123 (2006)

86. J. Baffreau, S. Leroy-Lhez, N. Vân Anh, R.M. Williams, P. Hudhomme, Chem. Eur. J. 14, 4974 (2008) 
P. Hudhomme: An overview of molecular acceptors for organic solar cells

87. J. Baffreau, L. Ordronneau, S. Leroy-Lhez, P. Hudhomme, J. Org. Chem. 73, $6142(2008)$

88. J. Baffreau, S. Leroy-Lhez, H. Derbal, A.R. Inigo, J.-M. Nunzi, M.M. Groeneveld, R.M. Williams, P. Hudhomme, Eur. Phys. J. Appl. Phys. 36, 301 (2006)

89. S.P. Singh, Ch.P. Kumar, G.D. Sharma, R. Kurchania, M.S. Roy, Adv. Funct. Mater. 22, 4087 (2012)

90. M. Jørgensen, K. Norrman, F.C. Krebs, Sol. Energy Mater. Sol. Cells 92, 686 (2008)

91. M. Drees, H. Hoppe, C. Winder, H. Neugebauer, N.S. Sariciftci, W. Schwinger, F. Schäffler, C. Topf, M.C. Scharber, Z. Zhu, R. Gaudiana, J. Mater. Chem. 15, 5158 (2005)
92. Y.-J. Cheng, F.-Y. Cao, W.-C. Lin, C.-H. Chen, C.-H. Hsieh, Chem. Mater. 23, 1512 (2011)

93. C.-H. Hsieh, Y.-J. Cheng, P.-J. Li, C.-H. Chen, M. Dubosc, R.-M. Liang, C.-S. Hsu, J. Am. Chem. Soc. 132, 4887 (2010)

94. Y.-J. Cheng, C.-H. Hsieh, Y. He, C.-S. Hsu, Y. Li, J. Am. Chem. Soc. 132, 17381 (2010)

95. C.-Y. Chang, C.-E. Wu, S.-Y. Chen, C. Cui, Y.-J. Cheng, C.-S. Hsu, Y.-L. Wang, Y. Li, Angew. Chem. Int. Ed. 50, 9386 (2011)

96. R.A.J. Janssen, J. Nelson, Adv. Mater. 25, 1847 (2013)

Cite this article as: Piétrick Hudhomme, An overview of molecular acceptors for organic solar cells, EPJ Photovoltaics 4, 40401 (2013). 